\title{
MENGUKUR TINGKAT MOTIVASI MASYARAKAT TERHADAP PEMANFAATAN PEKARANGAN UNTUK PERTANIAN PERKOTAAN DI KOTA YOGYAKARTA
}

\section{MEASURING THE LEVEL OF COMMUNITY MOTIVATION TOWARD HOUSE YARD UTILIZATION FOR URBAN AGRICULTURE IN YOGYAKARTA CITY}

\author{
*Defira Suci Gusfarina \\ Balai Pengkajian Teknologi Pertanian Jambi \\ Badan Penelitian dan Pengembangan Pertanian, Kementerian Pertanian RI
}

\author{
Irham \\ Fakultas Pertanian, Universitas Gadjah Mada
}

Submitted: 29-04-2018; Revised: 17-03-2019; Accepted: 04-04-2019

\begin{abstract}
Urban agriculture continues to grow in relation to environmental, economic, health and social issues, including in the city of Yogyakarta. The people of Yogyakarta City use the yard to grow vegetables and fruit. The economic, social, cultural, and psychological conditions of each household vary to be able to implement an innovation. In order to achieve sustainable yard utilization, the utilization of the yard must adjust to the motivation of the community. The purpose of this study is to determine the level of environmental, economic, health and social motivation of the community in utilizing the yard for farming. This study uses descriptive research methods with qualitative approaches and survey techniques using a questionnaire on 113 respondents. Motivation is measured using Likert scale from item statements. Each statement is given a score of 1 to 5 according to the answers provided. These answers are calculated, made into percentage and an interval scales is used as the reference for high, medium and low category. The results showed that the motivation of the people of Yogyakarta City sequentially from high to low were health motivation, environmental motivation, social/community motivation and economic motivation. Agricultural planning and policy in cities, especially in the yard, must pay special attention to multifunctional farming practices that are environmentally friendly as suppliers of healthy food for families, become a recreation area and a place for socializing and selfdevelopment so that leisure time become more productive.
\end{abstract}

Keywords: Motivation; Urban agriculture; Yard

\section{ABSTRAK}

Pertanian perkotaan terus berkembang dalam kaitannya dengan masalah lingkungan, ekonomi, kesehatan dan sosial, termasuk di Kota Yogyakarta. Masyarakat Kota Yogyakarta memanfaatkan pekarangan untuk

*Corresponding author: defirasucigusfarina@gmail.com.

Copyright@ 2019 THE AUTHOR(S). This article is distributed under a Creative Commons Attribution-Share Alike 4.0 International license. Jurnal Kawistara is published by the Graduate School of Universitas Gadjah Mada 
bertanam sayur dan buah. Kondisi ekonomi, sosial, budaya dan psikologi masing-masing rumah tangga berbeda-beda untuk dapat menerapkan suatu inovasi. Agar pemanfaatan pekarangan ini dapat berkelanjutan dan berkesinambungan, pemanfaatan pekarangan haruslah menyesuaikan motivasi masyarakat itu sendiri. Tujuan penelitian ini adalah untuk mengetahui tingkat motivasi lingkungan, ekonomi, kesehatan dan sosial/kemasyarakatan dalam memanfaatkan pekarangan untuk usaha tani. Penelitian ini menggunakan metode penelitian deskriptif dengan pendekatan kualitatif dan teknik survei menggunakan kuesioner kepada 113 responden. Motivasi diukur menggunakan skala Likert dari item pernyataan. Setiap pernyataan diberi skor 1 sampai dengan 5 sesuai dengan jawaban yang disediakan. Jawaban dihitung, dipersentasekan, dan skala interval digunakan untuk mengkategorikan motivasi tinggi, sedang, dan rendah. Hasil penelitian menunjukkan bahwa motivasi masyarakat Kota Yogyakarta secara berurutan dari yang tinggi ke rendah yaitu motivasi kesehatan, motivasi lingkungan, motivasi sosial/kemasyarakatan, dan motivasi ekonomi. Perencanaan dan kebijakan pertanian di perkotaan khususnya di pekarangan harus memberi perhatian khusus pada praktek pertanian multifungsi yang ramah lingkungan sebagai pemasok makanan yang sehat bagi keluarga, dapat menjadi wahana rekreasi, serta menjadi wadah bersosialisasi dan pengembangan diri agar waktu senggang menjadi lebih produktif.

\section{Kata kunci: Motivasi; Pekarangan; Pertanian perkotaan}

\section{PENGANTAR}

Studi tentang pertanian perkotaan terus berkembang dalam kaitannya dengan masalah lingkungan, ekonomi, kesehatan dan sosial kemasyarakatan (Mcclintock, 2010; Guitart, Pickering dan Byrne, 2012; Horst dkk, 2017). Pemanfaatan pekarangan untuk pertanian di perkotaan mempunyai potensi yang besar dan memberi banyak manfaat (Gray dkk, 2014) Lokasinya pun dapat dibedakan di pusat kota (intra-urban) dan pinggiran kota (peri-urban). Kondisi ekonomi, sosial, budaya dan psikologi masing-masing rumah tangga berbeda-beda dalam menerapkan suatu inovasi (Mohri dkk, 2013). Pada masyarakat perkotaan yang heterogen, sikap akan lingkungan berbeda pada setiap individu dan rumah tangga, sehingga berbeda pula motivasi masyarakat perkotaan untuk memanfaatkan pekarangan tersebut. Pemanfaatan pekarangan ini dapat berkelanjutan dan berkesinambungan, haruslah menyesuaikan dengan motivasi masyarakat itu sendiri.

Motivasi lingkungan menjadi motivasi utama masyarakat di beberapa kota besar, melaksanakan pertanian (Ciftcioglu, 2017; Trendov, 2018). Pertanian di perkotaan dapat memperbaiki kualitas udara, mengurangi panas kota, selain itu sampah organik rumah tangga dapat diolah dan dimanfaatkan untuk pertanian (Hubert dkk, 2010). Pada saat yang sama, pemanfaatan pekarangan juga memberikan manfaat estetik dan psikologis sebagai sarana rekreasi.

Motivasi ekonomi yang mendasari masyarakat perkotaan melakukan usahatani diantaranya sebagai sumber makanan keluarga, mengurangi pengeluaran, menambah pendapatan rumah tangga (Simatele dan Binns, 2008; Battersby dan Marshak, 2013), serta mengurangi biaya transportasi (Mcclintock, 2010). Kurangnya ruang terbuka hijau dan tingginya polusi udara di perkotaan juga akan mengganggu kesehatan masyarakat dalam jangka waktu pendek maupun panjang (Setyowati, 2008). Jarak dari sumber makanan yang jauh menumbuhkan kekhawatiran pada kualitas makanan yang mereka makan (Corrigan, 2011). Masyarakat kota mengakui makanan yang mereka produksi sendiri lebih segar, bergizi dan sehat (Gauder dkk, 2018). Namun manfaat kesehatan yang lebih luas adalah bagaimana berusahatani di pekarangan membantu mereka secara psikologis menanamkan kedisiplinan dan kesabaran dan juga menjaga kesehatan fisik (Dunn, 2010). Manfaat kesehatan menjadi motivasi yang mempengaruhi untuk ikut berpartisipasi dalam pemanfaatan pekarangan di perkotaan (Egli dkk, 2016).

Manfaat lain dari pertanian di perkotaan adalah tempat membangun komunitas dan sarana pendidikan (Turner, 2011). Motivasi pribadi utama individu mengambil bagian dalam pertanian perkotaan adalah adanya kesempatan bersosialisasi, dan juga melestarikan budaya menanam (Hovorka, 2008; Battersby dan Marshak, 2013). Di Indonesia 
sampai saat ini, penelitian pemanfaatan pekarangan sudah melihat prospek lahan pekarangan untuk mendukung ketahanan pangan di tingkat rumah tangga (Ashari dkk., 2012; Saptana dkk., 2013) dan kebanyakan dari penelitian masih berfokus pada menganalisis proyek kegiatan pemerintah (Andiani dkk., 2019; Metalisa dkk, 2014).

Kajian ini bertujuan untuk mengukur tingkat: motivasi lingkungan; motivasi ekonomi; motivasi kesehatan; dan motivasi sosial/kemasyarakatan masyarakat dalam pemanfaatan pekarangan untuk pertanian di perkotaan. Analisis empat motivasi ini diharapkan dapat menjadi masukan dan bahan pertimbangan bagi pengambil kebijakan, motivasi utama yang mendukung berkembangnya pertanian di perkotaan sehingga pengembangan pertanian perkotaan dapat tepat sasaran, berkelanjutan dan berkesinambungan.

Penelitian ini dilakukan di Kota Yogyakarta, di mana masyarakat yang memanfaatkan pekarangan untuk berusahatani sayur dan/ atau buah tergabung dalam kelompok tani yang sudah berdiri sejak tahun 1979 sampai saat ini. Kelompok tani ini bergerak dibidang tanaman pangan dan hortikultura yang tersebar di 14 kecamatan, dengan beberapa komoditas unggulan diantaranya: hortikultura, tanaman hias, anggrek, tanaman pangan, tanaman sayuran, tabulampot (tanam buah dalam pot), jamur, bunga potong dan olahan hasil pertanian.

Penelitian ini menggunakan metode penelitian deskriptif dengan pendekatan kualitatif dan teknik survei menggunakan kuesioner. Motivasi diukur menggunakan skala likert dari item pernyataan (Tabel 1). Setiap pernyataan diberi skor 1 sampai dengan 5 sesuai dengan jawaban yang disediakan yaitu SI = Sangat Ingin, I = Ingin, N = Netral, TI = Tidak Ingin, STI $=$ Sangat Tidak Ingin. Jawaban dihitung, dipersentasekan dan skala interval digunakan untuk mengkategorikan motivasi tinggi, sedang dan rendah.

Tabel 1.

Item Pernyataan Pengukuran Motivasi Lingkungan, Motivasi Ekonomi, Motivasi Kesehatan dan Motivasi Sosial/Kemasyarakatan

\begin{tabular}{|c|c|c|c|c|}
\hline No & Lingkungan & Ekonomi & Kesehatan & Sosial/Kemasyarakatan \\
\hline 1 & $\begin{array}{l}\text { Keinginan memberi warna } \\
\text { pada pekarangan dengan } \\
\text { menanam sayuran buah } \\
\text { (terong, tomat, dan cabai) }\end{array}$ & $\begin{array}{l}\text { Keinginan mengurangi } \\
\text { pengeluaran }\end{array}$ & $\begin{array}{l}\text { Keinginan memberi- } \\
\text { kan makanan yang } \\
\text { hiegienis bebas pesti- } \\
\text { sida bagi keluarga }\end{array}$ & $\begin{array}{l}\text { Keinginan bergabung } \\
\text { dengan kelompok tani }\end{array}$ \\
\hline 2 & $\begin{array}{l}\text { Keinginan menjadikan } \\
\text { pekarangan terlihat } \\
\text { indah dengan bertanam } \\
\text { sayuran/buah }\end{array}$ & $\begin{array}{l}\text { Keinginan mengurangi } \\
\text { biaya transportasi ke } \\
\text { warung/super market } \\
\text { untuk membeli sayuran }\end{array}$ & $\begin{array}{l}\text { Keinginan mem- } \\
\text { berikan makanan } \\
\text { yang bermutu bagi } \\
\text { keluarga }\end{array}$ & $\begin{array}{l}\text { keinginan menjadi tempat } \\
\text { orang-orang bertanya } \\
\text { tentang bertanam buah } \\
\text { dan sayur }\end{array}$ \\
\hline 3 & $\begin{array}{l}\text { Keinginan menjadikan } \\
\text { rumah terasa sejuk dan } \\
\text { nyaman dengan adanya } \\
\text { tanaman sayuran/buah }\end{array}$ & $\begin{array}{l}\text { Keinginan mengurangi } \\
\text { biaya untuk liburan } \\
\text { dengan merawat } \\
\text { tanaman }\end{array}$ & $\begin{array}{l}\text { Keinginan } \\
\text { memberikan } \\
\text { makanan yang segar } \\
\text { bagi keluarga }\end{array}$ & $\begin{array}{l}\text { Keinginan berbagi hasil } \\
\text { panen dengan tetangga } \\
\text { atau tamu yang dating }\end{array}$ \\
\hline 4 & $\begin{array}{l}\text { Keinginan menjadikan } \\
\text { udara diluar rumah terasa } \\
\text { lebih segar }\end{array}$ & $\begin{array}{l}\text { Keinginan memanfaat- } \\
\text { kan waktu senggang } \\
\text { menjadi lebih produktif }\end{array}$ & $\begin{array}{l}\text { Keinginan } \\
\text { memperbaiki gizi } \\
\text { kelurarga }\end{array}$ & $\begin{array}{l}\text { Keinginan mengikuti } \\
\text { tetangga yang juga ber- } \\
\text { tanaman buah dan sayuran }\end{array}$ \\
\hline 5 & $\begin{array}{l}\text { Keinginan membuat } \\
\text { halaman rumah tidak } \\
\text { terlihat gersang }\end{array}$ & $\begin{array}{l}\text { Keinginan memanfaat- } \\
\text { kan sampah organik } \\
\text { untuk membuat pupuk } \\
\text { yang digunakan untuk } \\
\text { tanaman sendiri }\end{array}$ & $\begin{array}{l}\text { Keinginan untuk } \\
\text { dapat menyegarkan } \\
\text { pikiran }\end{array}$ & $\begin{array}{l}\text { Keinginan sebagai sarana } \\
\text { edukasi, mendidik } \\
\text { anggota keluarga dan } \\
\text { masyarakat untuk cinta } \\
\text { lingkungan }\end{array}$ \\
\hline 6 & $\begin{array}{l}\text { Keinginan memanfaatkan } \\
\text { barang bekas rumah tangga } \\
\text { untuk digunakan sebagai } \\
\text { wadah tanam (botol bekas, } \\
\text { wadah minyak goreng, } \\
\text { kaleng susu/roti, dsb) }\end{array}$ & & $\begin{array}{l}\text { Keinginan } \\
\text { menciptakan } \\
\text { keanekaragaman } \\
\text { makananan } \\
\text { keluarga }\end{array}$ & $\begin{array}{l}\text { Keinginan melestarikan } \\
\text { budaya menanam }\end{array}$ \\
\hline
\end{tabular}

Sumber: Analisis Data (2018) 
Item-item pernyataan ini sudah diuji validitas dan reliabilitasnya sebelum digunakan. Item valid didasarkan pada nilai "Corrected Item-Total Correlation" untuk masing-masing item pernyataan yang lebih besar dari 0,30 dan item pernyataan reliabel didasarkan pada nilai Cronsbach's Alpha yang lebih besar dari 0,60 (Sugiyono, 2010).

Teknikpengambilansampellokasipenelitian dilakukan dengan menggunakan teknik purposive sampling. Penelitian ini mengambil lokasi di 7 kecamatan dari 11 kecamatan yang ada di Kota Yogyakarta kecamatan ini dibagi dalam 2 lokasi yaitu lokasi pusat kota dan pinggiran kota. Agar mempermudah memperoleh responden yang memanfaatkan pekarangan untuk usaha tani sayur dan/atau buah tiap 1 kecamatan diambil 1 kelurahan. Pertimbangan 7 kecamatan tersebut dijadikan sampel karena memiliki banyak kelompok tani yang mengusahakan pekarangan untuk pertanian hortikultura, sedangkan untuk pemilihan lokasi kelurahan dengan melihat keragaman komoditas hortikultura yang menjadi unggulan sehingga diharapkan sampel memenuhi keragaman. Kecamatan dan kelurahan tersebut adalah Kecamatan Keraton dan Kelurahan Kadipaten; Kecamatan Gondokusuman dan Kelurahan Demangan; Kecamatan Danurejan dan Kelurahan Bausasran; Kecamatan Gondomanan dan Kelurahan Ngupasan; dan Kecamatan Jetis dan Kelurahan Cokrodiningrat untuk lokasi pusat kota. Kecamatan Kota Gede dan Kelurahan Rejowinangun dan Kecamatan Umbulharjo dan Kelurahan Warungboto untuk lokasi pinggiran kota.

Metode penentuan responden dilakukan dengan Simple Random Sampling pada rumahrumah yang memanfaatkan pekarangan untuk bertanam sayur dan/atau buah. Diperoleh 113 responden, yang terdiri dari 77 responden di lokasi pusat kota dan 36 responden pinggiran kota.

\section{PEMBAHASAN \\ Karakteristik Responden}

Responden dalam penelitian ini sebagian besar adalah perempuan baik itu di pusat kota maupun di pinggiran kota (Tabel 2). Ini berarti pemanfaatan pekarangan memang menjadi wilayah pekerjaan ibu-ibu, terutama ibu rumah tangga yang sehari-hari berada di rumah. Jumlah responden laki-laki di lokasi pusat kota lebih rendah dari responden pusat kota ini berarti laki-laki di pinggiran kota lebih aktif dalam pemanfaatan pekarangan dari pada lakilaki di pusat kota. Hal ini dikarenakan laki-laki di lokasi pinggiran kota memiliki keleluasaan waktu memanfaatkan pekarangan untuk berusahatani sayur dan/atau buah.

Jumlah responden berumur 25-42 tahun di pusat kota jauh lebih sedikit dari responden pinggiran kota pada umur yang sama, hal ini disebabkan masyarakat yang berumur 25-42 tahun di pusat kota tidak banyak yang memanfaatkan pekarangan untuk berusahatani sayur dan/atau buah karena banyak pekerjaan sampingan lain yang tersedia di pusat kota untuk masyarakat dengan umur 24-42 tahun tersebut di bandingkan dengan lokasi pinggiran kota.

Lebih dari setengah responden Kota Yogyakarta berusia antara 43-60 tahun, di usia ini pada umumnya responden memiliki anak yang sudah mandiri dan bahkan responden ada yang sudah memasuki masa pensiun, sehingga waktu luang yang ada digunakan untuk merawat tanaman sayur dan/atau buah di pekarangan.

Responden di Kota Yogyakarta memiliki pendidikan yang cukup tinggi, lebih dari setengah responden berpendidikan SMA/ sederajat ke atas. Pendidikan berpengaruh pada motivasi dengan pertimbangan secara umum bahwa tingkat pendidikan mencerminkan tingkat pemahaman daya nalar dan pemahaman masyarakat dalam menilai baik buruknya lingkungan bagi dirinya.

Pengalaman responden dalam berusahatani sayur dan/atau buah di pekarangan di Kota Yogyakarta cenderung masih rendah antara 1-8 tahun. Pengalaman berpengaruh pada motivasi, semakin banyak pengalaman, semakin terasa manfaat yang diperoleh dalam berusahatani di pekarangan. Semakin terasa manfaatkan semakin tinggi motivasi masyarakat memanfaatkan pekarangan untuk pertanian. 
Tabel 2.

Karakteristik responden

\begin{tabular}{lccc}
\hline & \multicolumn{1}{c}{$\begin{array}{c}\text { Pusat Kota } \\
(\mathbf{N}=77)\end{array}$} & $\begin{array}{c}\text { Pinggiran Kota } \\
(\mathbf{N}=36)\end{array}$ & $\begin{array}{c}\text { Kota Yogyakarta } \\
\mathbf{( N = 1 1 3 )}\end{array}$ \\
\hline Jenis Kelamin & & & 21,2 \\
Laki-laki (\%) & 14,3 & 36,1 & 78,8 \\
Perempuan (\%) & 85,7 & 63,9 & 15,9 \\
\hline Umur & & & 62,8 \\
25-42 tahun (\%) & 7,8 & 33,3 & 21,2 \\
43-60 tahun (\%) & 68,8 & 50,0 & \\
61-78 tahun (\%) & 23,4 & 16,7 & 8,9 \\
\hline Tingkat pendidikan & & & 13,3 \\
SD (\%) & 7,8 & 11,1 & 50,4 \\
SMP (\%) & 13,0 & 13,9 & 11,4 \\
SMA/Sederajat (\%) & 51,9 & 47,2 & 15,9 \\
D1/D2/D3 (\%) & 10,4 & 13,9 & 77,9 \\
D4/S1/S2 (\%) & 16,9 & 13,9 & 17,7 \\
\hline Pengalaman & & & 4,4 \\
berusahatani & 80,5 & 72,2 & \\
1-8 tahun (\%) & 15,6 & 22,2 & \\
19-36 tahun (\%) & 3,9 & 5,6 & \\
37-54 tahun (\%) & & & \\
\hline
\end{tabular}

Sumber: Analisis Data (2018)

\section{Motivasi Responden}

Penelitian ini melihat dari 4 motif pemanfaatan pekarangan untuk bertanam sayur dan/atau buah yaitu motivasi lingkungan, motivasi ekonomi, motivasi kesehatan dan motivasi sosial/kemasyarakatan.

\section{Motivasi Lingkungan}

Motivasi lingkungan (Gambar 1) menggambarkan bahwa memanfaatkan pekarangan untuk bertanam sayur dan/atau buah adalah karena keinginan memberi warna, dengan aneka warna yang dihasilkan tanaman sayur misalnya merah dari cabai dan tomat, ungu dari terung atau sayur daun seperti bayam merah, bayam hijau serta tanaman aneka buah. Berbeda dengan tanaman bunga, tanaman sayur dan buah bukan hanya bisa dinikmati mata namun sekaligus dapat dinikmati untuk konsumsi. Pada pekarangan lokasi pusat kota dan lokasi pinggiran kota (pernyataan 1) tidak berbeda jauh, dengan adanya tanaman sayur dan/atau buah di pekarangan memberi warna yang berbeda pada pekarangan mereka dibandingkan dengan hanya bertanam bunga.
Keinginan menjadikan pekarangan terlihat indah (pernyataan 2), rumah terasa sejuk dan nyaman (pernyataan 3) di pusat kota lebih rendah dari pinggiran kota yang $100 \%$. Hal ini dikarenakan beberapa responden pusat kota yang menanam sayur, tidak segera menanam kembali karena menunggu ada waktu luang, sehingga pot-pot yang kosong setelah panen menurut mereka tidak nyaman untuk dilihat.

Keinginan menjadikan udara di luar rumah terasa lebih segar (pernyataan 4) pusat kota dan pinggiran kota hampir sama, sebagian besar responden merasakan manfaat udara di luar rumah terasa lebih segar, dengan adanya oksigen yang dikeluarkan oleh tanaman sayur dan/atau buah. Keinginan membuat halaman rumah tidak gersang (pernyataan 5) lokasi pusat kota lebih rendah dari lokasi pinggiran kota yang seratus $100 \%$, ini berarti masyarakat di pinggiran kota yang pekarangannya cenderung lebih luas sangat menghargai tanaman sayur dan/atau buah untuk penghijauan agar halaman tidak kelihatan gersang. Keinginan memanfaatkan barang bekas rumah tangga untuk media tanam (pernyataan 6) di pusat kota sedikit lebih tinggi dari pada pinggiran 
kota. Barang bekas yang biasa digunakan untuk media tanam adalah seperti bungkus minyak goreng atau deterjen yang memang ada dan selalu digunakan di rumah serta botol plastik bekas minuman untuk wadah tanam vertikultur.

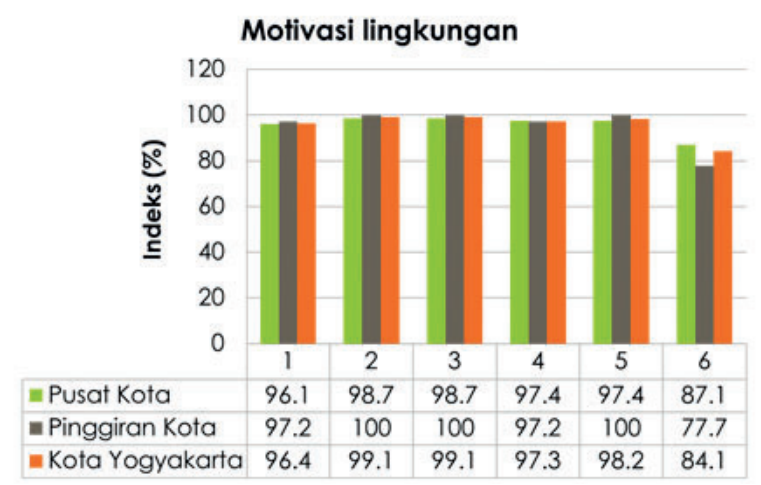

Gambar 1

Diagram Motivasi Lingkungan

Sumber: Analisis data primer (2018)

Motivasi lingkungan dari Kota Yogyakarta untuk bertanam sayur dan/atau buah yang pertama adalah keinginan menjadikan pekarangan terlihat indah, terasa sejuk dan nyaman. Kedua adalah keinginan membuat halaman rumah tidak gersang, diikuti menjadikan udara di luar rumah terasa lebih segar, memberi warna pada pekarangan, dan terakhir memanfaatkan barang bekas rumah tangga. Memanfaatkan barang bekas kurang menjadi motivasi masyarakat karena mereka merasa dengan memanfaatkan barang bekas mengurangi keindahan dari tanaman tersebut mereka cenderung untuk membeli pot atau paralon untuk vertikultur.

\section{Motivasi Ekonomi}

Pada Gambar 2 dapat dilihat pernyataan pertama motivasi ekonomi responden adalah keinginan mengurangi pengeluaran untuk membeli sayur dan/atau buah di lokasi pusat kota dan pinggiran kota tidak jauh berbeda. Hal ini pun berlaku sama untuk pernyataan kedua apakah keinginan mengurangi biaya transportasi ke warung/super market/pasar untuk membeli sayur dan/atau buah.

Pernyataan ketiga apakah yang menjadi motivasi ekonomi responden adalah keinginan mengurangi biaya untuk liburan dengan merawat tanaman. Lokasi pusat kota dan lokasi pinggiran kota sangat jauh berbeda, hal ini menggambarkan bahwa merawat pekarangan untuk lokasi pinggiran kota tidak mengurangi biaya untuk liburan, karena mereka beranggapan rekreasi dengan merawat tanaman dan rekreasi dengan liburan bukan sesuatu yang bisa saling menggantikan, mereka tetap akan meluangkan waktu untuk liburan dengan jalan-jalan, sedangkan masyarakat pusat kota sebagian besar meyakini merawat tanaman bisa mengurangi biaya untuk liburan.

Hasil penelitian (Mulato, 2008) mendukung hal ini menunjukkan ketersediaan ruang terbuka hijau di perkotaan berpengaruh pada aktivitas rekreasi masyarakat dalam skala lingkungan perumahan di perkotaan. Di tengah tren aktivitas rekreasi masyarakat kota saat ini, seperti jalan-jalan ke pusat perbelanjaan baik untuk belanja atau pun sekedar cuci mata, jajan atau makan-makan, ketersediaan pekarangan yang hijau cukup memberikan motivasi hiburan murah, dengan waktu singkat dan jarak yang dekat.

Keinginan memanfaatkan waktu senggang menjadi lebih produktif (pernyataan keempat) benar-benar menjadi motivasi responden pinggiran kota dimana nilainya $100 \%$, sedangkan beberapa masyarakat pusat kota beranggapan mereka bukan memanfaatkan waktu senggang, tetapi merawat tanaman sudah menjadi rutinitas.

Keinginan memanfaatkan sampah organik untuk membuat pupuk yang digunakan untuk tanaman sendiri (Pernyataan kelima). Kompos sampah organik dapat menggantikan penggunaan pupuk kimia dan mengurangi biaya produksi (Sulistyawati dan Nugraha, 2015). Keinginan memanfaatkan pupuk organik ini lokasi pusat kota cukup tinggi dibandingkan dengan pinggiran kota, beberapa responden pinggiran kota beralasan tidak mempunyai tempat atau lokasi untuk membuat pupuk organik, bahkan mereka tidak suka dengan baunya, mereka lebih cenderung untuk membeli pupuk yang sudah siap pakai. Di sini perlu adanya keterlibatan penyuluh untuk menyampaikan cara membuat pupuk organik 
yang ramah lingkungan, selain mengurangi biaya usahatani untuk pembelian pupuk.

Motivasi ekonomi masyarakat Kota Yogyakarta dalam memanfaatkan pekarangan untuk bertanam sayur dan/atau buah secara berurutan adalah keinginan memanfaatkan waktu senggang, keinginan mengurangi pengeluaran, keinginan memanfaatkan sampah organik, keinginan mengurangi biaya transportasi ke warung/pasar/super market, keinginan menambah pendapatan rumah tangga pada urutan kelima dan keinginan mengurangi biaya untuk liburan pada urutan terakhir.

Pemanfaatan pekarangan di Kota Yogyakarta, belum bisa memenuhi kebutuhan sayur dan buah rumah tangga di Kota Yogyakarta, hal ini disebabkan belum maksimalnya pemanfaatan pekarangan dan belum bervariasinya tanaman di pekarangan sesuai kebutuhan rumah tangga. Ketersediaan sayur dan buah untuk kebutuhan hidup sehari-hari di Kota Yogyakarta relatif murah dan mudah diakses juga turut mendukung motivasi ekonomi bukan menjadi motivasi utama masyarakat Kota Yogyakarta memanfaatkan pekarangan untuk bertanam sayur dan/atau buah.

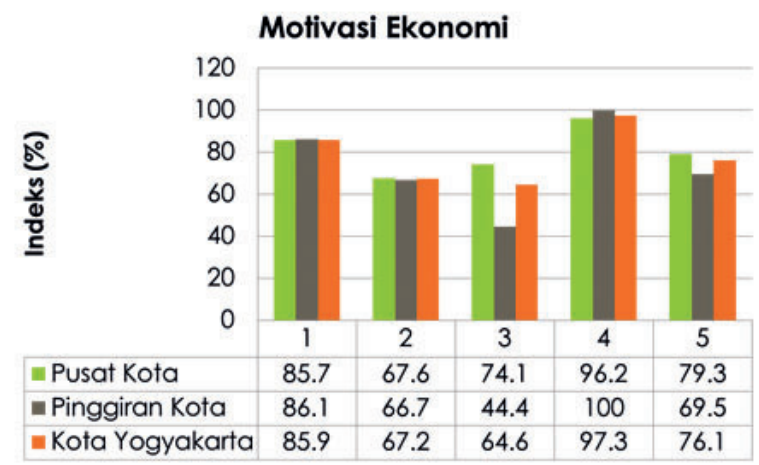

Gambar 2

Diagram motivasi ekonomi

Sumber : Analisis Primer (2018)

Hasil ini berbeda dengan beberapa hasil penelitian yang menyatakan pertanian di perkotaan bukan hanya meningkatkan ketersediaan makanan yang segar dan bergizi dan mengakibatkan ketahanan pangan individu, juga mengurangi pengeluaran untuk membeli makanan (Rezai dkk, 2016) serta menambah pendapatan (Dubbeling dan de Zeeuw, 2011) so do the food needs of urban families.
The situation of the urban poor is precarious in the present context of volatile food prices and the financial, fuel and economic crises. The urban poor, often located in the most vulnerable parts of cities and lacking the capacity to adapt to climaterelated impacts, will be hit hardest. The challenges associated with supporting the urban poor demand urgent and adequate responses from city and national authorities and international organisations. Urban policies need to incorporate food security considerations and focus more on building cities that are more resilient to crises. There is growing recognition of urban and peri-urban agriculture (UPA. Perbedaan ini disebabkan perbedaan pada karakteristik responden, seperti tingkat pendapatan responden.

\section{Motivasi Kesehatan}

Gambar 3 memperlihatkan motivasi kesehatan diukur dari pernyataan, apakah memanfaatkan pekarangan untuk bertanam sayur dan/atau buah karena ingin memberikan makanan yang hiegienis bebas pestisida (pernyataan 1), bermutu (pernyataan 2), segar (pernyataan 3) bagi keluarga untuk lokasi pusat kota sama sedangkan lokasi pinggiran kota $100 \%$ untuk pernyataan 1, 2 dan 3 ini. Hal ini disebabkan masyarakat pinggiran kota yang masih berusaha menjaga kesehatan dengan menjaga makanan.

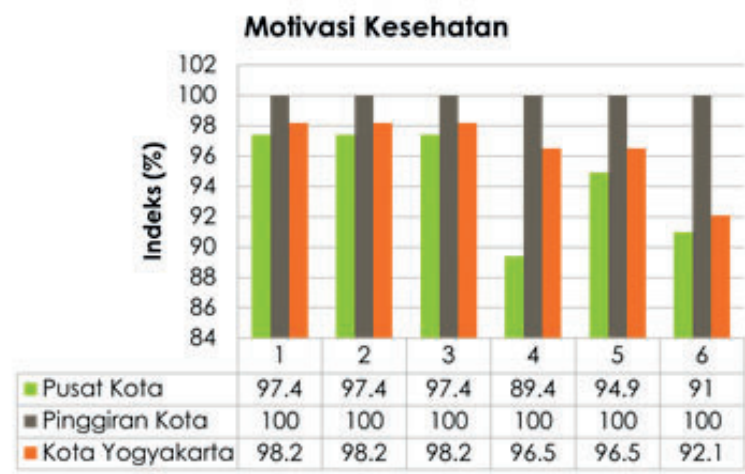

Gambar 3

Diagram motivasi kesehatan

Sumber: Analisis Primer (2018)

Keinginan memperbaiki gizi keluarga (pernyataan 4) dan untuk dapat menyegarkan pikiran (pernyataan 5) untuk lokasi pusat kota masing-masing adalah $89,5 \%$ dan $94,4 \%$, 
sedangkan lokasi pinggiran kota tetap 100\% untuk pernyataan ini. Masyarakat pusat kota sepertinya lebih berpikiran bahwa memperbaiki gizi tidak hanya bisa dilakukan dengan menanam sendiri sayur dan/atau buah, begitu pun dengan menyegarkan pikiran mereka cenderung untuk menanam bunga hias. Pada pernyataan terakhir (pernyataan 6) apakah keinginan menanam sayur dan/atau buah adalah menciptakan keanekaragaman makanan bagi keluarga, untuk masyarakat pinggiran kota pernyataan ini bernilai rendah dari pernyataan lainnya, hal ini dikarenakan anggapan bahwa tanaman yang mereka tanam tidak terlalu beragam.

Motivasi kesehatan yang paling kuat untuk Kota Yogyakarta adalah untuk memberikan makanan yang hiegienis bebas pestisida, bermutu, dan segar bagi keluarga. Sejalan dengan persyaratan kualitas sayuran untuk konsumsi rumah tangga di lingkungan perkotaan yaitu sayur yang segar terbebas dari noda dan kerusakan (Agbayani dkk, 2001) dan ini bisa didapatkan dengan mereka menanam sendiri di pekarangan. Kedua adalah keinginan memperbaiki gizi keluarga dan dapat menyegarkan pikiran yang menjadi alasan terakhir adalah menciptakan keanekaragaman makanan keluarga.

Ketersediaan sayur dan buah di kota yang relatif murah dan mudah untuk di akses, tidak memberi jaminan buah dan sayuran itu hiegenis dan bebas pestisida serta buah dan sayur yang diimpor dari luar Kota Yogyakarta juga kesegarannya berkurang selama pengangkutan menjadikan motivasi kesehatan ini sangat kuat.

\section{Motivasi Sosial/kemasyarakatan}

Gambar 4 menyajikan pernyataan untuk mengukur motivasi sosial/kemasyarakatan responden. Pernyataan pertama, apakah memanfaatkan pekarangan untuk bertanam sayur dan/atau buah adalah agar bisa bergabung dengan kelompok tani di lokasi pusat kota lebih tinggi dari pada pinggiran kota ini berarti di pusat kota cenderung haus akan sosialisasi berhubungan dengan tetangga salah satu caranya adalah tergabung dalam wadah yang satu visi dan misi.
Pernyataan kedua, apakah responden berkeinginan menjadi tempat orang-orang bertanya tentang bertanam sayur dan/atau buah di pusat kota lebih tinggi dari pada di pinggiran kota. Hal ini menjelaskan bahwa pada masyarakat pusat kota ingin dianggap berkompeten di bidang pertanian yang jarang ada di perkotaan, sedangkan di pinggiran kota mereka lebih cenderung menganggap ilmu mereka tentang bertanam di pekarangan itu sama.

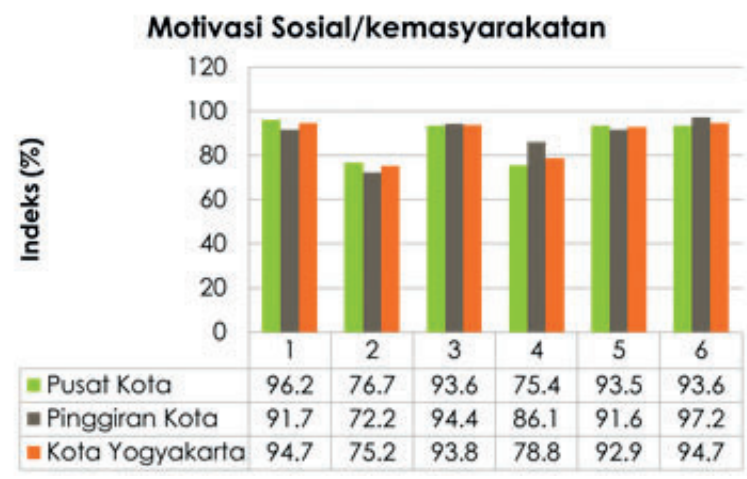

Gambar 4

Motivasi sosial/ kemasyarakatan Sumber: Analisis Primer (2018)

Pernyataan ketiga, apakah didorong keinginan berbagi hasil panen dengan tetangga atau tamu yang berkunjung. Di pusat kota dan pinggiran kota tidak berbeda jauh. Mereka dengan senang hati berbagi hasil pekarangan mereka dengan tetangga.

Pernyataan keempat, mengikuti tetangga yang juga bertanam sayur dan/atau buah di pusat kota lebih rendah dari pada pinggiran kota. Masyarakat pusat kota cenderung memiliki sifat yang tidak ikut-ikutan atau tidak suka dikatakan ikut-ikutan.

Pernyataan kelima, keinginan sebagai sarana edukasi, mendidik anggota keluarga dan masyarakat untuk cinta lingkungan. Di pusat kota lebih tinggi dari pinggiran kota. Lokasi kota yang padat jauh dari suasana asri pedesaan, memotivasi sebagian besar masyarakat pusat kota untuk menghidupkan suasana asri di rumah mereka sehingga diharapkan dapat mengajarkan pada lingkungan mereka pentingnya tanaman di pekarangan, dapat menunjukkan kepada 
anak dan cucu mereka berbagai macam jenis sayuran, sambil menjelaskan manfaatnya.

Pernyataan keenam melestarikan budaya menanam di pinggiran kota lebih tinggi dari pada pusat kota. Masyarakat pinggiran kota cenderung melihat ke arah pusat kota dimana budaya menanam sudah hilang dan mereka termotivasi untuk tetap bertanam walaupun hanya di pekarangan. Beberapa responden mengatakan dengan bertanam sayur/buah di pekarangan mengingatkan mereka pada masa lalu yang menyenangkan. Pohon dan tanaman menyimpan memori bukan hanya berupa ingatan visual, tetapi dalam bentuk perasaan juga. Kenangan tempat bermain anak-anak, interaksi sosial dengan anak-anak, suami/istri, teman, orang tua, kakek dan nenek, menjadikan beberapa tanaman tertentu memiliki arti khusus yang tetap ingin dilestarikan (Mazumdar dan Mazumdar, 2012).

Motivasi sosial/kemasyarakatan yang paling utama responden di Kota Yogyakarta adalah keinginan bergabung dengan kelompok tani dan melestarikan budaya menanam, lalu secara berturut-turut keinginan berbagi hasil panen dengan tetangga atau tamu yang berkunjung, keinginan sebagai sarana edukasi, mendidik anggota keluarga dan masyarakat untuk cinta lingkungan, keinginan mengikuti tetangga yang juga bertanam sayur dan/atau buah dan terakhir keinginan menjadi tempat orang-orang bertanya tentang bertanam sayur dan/atau buah.

Motivasi sosial/kemasyarakatan pemanfaatan pekarangan adalah sebagai sarana untuk memperkuat komunitas dengan menyediakan tempat bertemu dan menikmati waktu berkualitas bersama keluarga dan teman-teman di lingkungan alam yang bersih dan tenang (Holmer, 2015).

\section{Motivasi memanfaatkan pekarangan di Kota Yogyakarta}

Pada responden pusat kota yang menjadi motivasi utama memanfaatkan pekarangan untuk bertanam sayur dan/atau buah adalah motivasi kesehatan, menjaga sayur yang mereka makan hiegienis bebas dari residu pestisida, bermutu dan dalam keadaan segar.
Hasil ini bisa dilihat di gambar 5. Di pinggiran kota juga sama motivasi kesehatan, tetapi bukan hanya agar makan hiegienis bebas dari residu pestisida, bermutu, dan dalam keadaan segar tetapi juga bisa mendapatkan makanan yang bergizi, selain itu juga menyegarkan pikiran.

Motivasi kedua di pusat kota adalah motivasi lingkungan agar lingkungan terlihat indah, terasa sejuk dan nyaman. Di pinggiran kota yang menjadi motivasi kedua adalah motivasi sosial/kemasyarakatan dimana mereka berkeinginan melestarikan budaya menanam yang mulai hilang.

Urutan ketiga untuk pusat kota adalah motivasi sosial/kemasyarakatan yaitu keinginan bergabung dengan kelompok tani, di urutan ketiga pinggiran kota adalah motivasi lingkungan keinginan agar pekarangan terlihat indah, terasa sejuk dan nyaman serta halaman tidak terlihat gersang.

Motivasi ekonomi menjadi motivasi terakhir masyarakat kota dan pinggiran kota dengan memanfaatkan pekarangan untuk bertanam sayur dan/atau buah adalah untuk memanfaatkan waktu senggang menjadi lebih produktif. Hal ini sedikit berbeda dengan di perdesaan di DIY pada penelitian (Putri, 2017), dimana tujuan pemanfaatan pekarangan masyarakat Desa Taman Tirto, Kabupaten Bantul adalah untuk memenuhi kebutuhan pangan keluarga berupa penghematan pengeluaran. Hal ini bisa disebabkan di perkotaan akses untuk membeli sayuran sangat mudah dan murah, sedangkan di desa bisa saja sulit karena jarak yang jauh dan transportasi yang kurang tersedia.

Secara keseluruhan untuk Kota Yogyakarta yang menjadi motivasi masyarakat berturut-turut adalah motivasi kesehatan, lingkungan, sosial/kemasyarakatan, dan terakhir ekonomi adalah tinggi. Hasil ini cukup selaras dengan hasil penelitian Specht dkk (2016) yang menunjukkan penerimaan tertinggi masyarakat untuk pertanian di perkotaan komersial haruslah multifungsi dengan tujuan lingkungan dan sosial sedangkan pertanian yang murni berbasis produksi atau berteknologi intensif cenderung 
ditolak, sehingga untuk menarik partisipasi aktif masyarakat haruslah menekankan pada tujuan-tujuan kesehatan, lingkungan bukan tujuan ekonomi sesuai dengan hasil penelitian bahwa kegagalan dari pertanian perkotaan adalah adanya penekanan berlebihan pada tujuan keuangan (Poulsen, 2017).

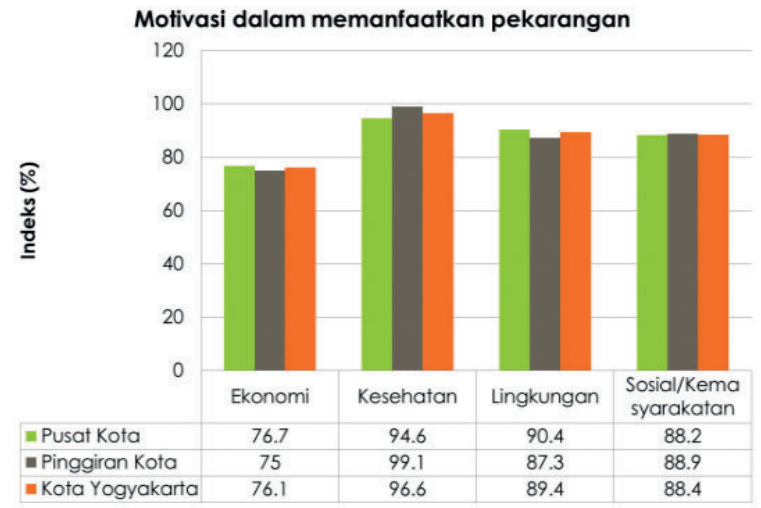

Gambar 5

Motivasi dalam memanfaatkan pekarangan Sumber: Analisis Primer (2018)

\section{SIMPULAN}

Motivasi masyarakat dalam pemanfaatan pekarangan untuk pertanian (bertanam sayur dan buah) di Kota Yogyakarta dari yang tinggi ke rendah secara berturut-turut yaitu motivasi kesehatan, motivasi lingkungan, motivasi sosial/kemasyarakatan dan terakhir motivasi ekonomi. Perencanaan pertanian di perkotaan mengandung banyak tujuan yang mungkin mengandung konflik antara pemerintah dan masyarakat, atau bahkan dengan alam dan lingkungan. Pendekatan pemerintah dalam pengembangan pertanian di perkotaan haruslah disesuaikan dengan motivasi masyarakat kota itu sendiri yang sangat berbeda dengan masyarakat desa agar tujuan itu tercapai.

Implikasi dari kajian empat motivasi pemanfaatan pekarangan di perkotaan adalah perlunya bagi pengambil kebijakan untuk memberikan perhatian terhadap multifungsi pekarangan di perkotaan, yaitu (1) pengembangan sistem pertanian yang ramah lingkungan, (2) pemasok makanan yang sehat bagi keluarga, (3) wahana rekreasi bagi keluarga dengan keindahan, kesejukan dan kenyamanan lingkungan rumah dan (4) sebagai wadah bersosialisasi dan pengembangan diri, sehingga waktu senggang menjadi lebih produktif.

\section{DAFTAR PUSTAKA}

Agbayani A.L.P, R. J. Holmer, G. E. Potutan, dan W. H. Schnitzler. 2001. Quality and Quantity Requirements for Vegetables by Private Households, Vendors and Institutional Users in a Philippine Urban Setting. Urban Agriculture Magazine, 5 : 56-57.

Andiani, R. Harsoyo dan Subejo. 2019. Motivasi Warga dalam Pelaksanaan Program Demplot Urban Farming di Kawasan Kampung Marunda Kecamatan Cilincing Jakarta Utara. Agritech: Jurnal Fakultas Pertanian Universitas Muhammadiyah Purwokerto, 20(2): 49-60.

Ashari, Saptana, dan T. B. Purwantini. 2012. Potential Use of Backyard Land for Food Security. Forum Penelitian Agro Ekonomi, 30(1): 13-30.

Battersby, J. dan M. Marshak. 2013. Growing Communities: Integrating the Social and Economic Benefits of Urban Agriculture in Cape Town. Urban Forum, 24(4): 447-461.

Ciftcioglu, G. C. 2017. Assessment Of The Resilience of Socio-Ecological Production Landscapes and Seascapes: A Case Study From Lefke Region of North Cyprus. Ecological Indicators, 73: 128 -138.

Corrigan, M. P. 2011. Growing What You Eat: Developing Community Gardens in Baltimore, Maryland. Applied Geography, 31(4): 1232-1241.

Dubbeling, M. dan de Zeeuw, H. 2011. Urban Agriculture and Climate Change Adaptation: Ensuring Food Security Through Adaptation. Resilient Cities, 441-449.

Dunn, A. D. 2010. Siting Green Infrastructure: Legal and Policy Solutions to 
Alleviate Urban Poverty and Promote Healthy Communities. Environmental Affairs Law Review, 37(1): 41-67.

Egli, V., M. Oliver, dan E. Tautolo. 2016. The Development of a Model of Community Garden Benefits to Wellbeing. Preventive Medicine Reports, 3: 348 -352.

Gauder, M., H. Hagel. N. Gollmann, J. Stangle, R. Doluschitz, dan W. Claupein. 2017. Motivation and Background of Participants and Providers of Self-Harvest Gardens in Germany. Renewable Agriculture and Food Systems, 1-9.

Gray, L., P. Guzman, K. M. Glowa, dan A. G. Drevno. 2014. Can Home Gardens Scale Up Into Movements for Social Change? The Role Of Home Gardens in Providing Food Security and Community Change in San Jose, California. Local Environment: The International Journal of Justice and Sustainability, 19 (20): 187-203.

Guitart, D., C. Pickering, dan J. Byrne. 2012. Urban Forestry and Urban Greening Past Results and Future Directions in Urban Community Gardens Research. Urban Forestry \& Urban Greening, 11(4): 364-373.

Holmer, R. 2015.Community-Based Vegetable Production Systems : An Answer to the Food and Sanitation Crisis of Urban Poor in the Philippines? Community-Based Vegetable Production Systems : An Answer to the Food and Sanitation Crisis of Urban Poor in the Philippines?. Acta horticulturae, 881: 125-130.

Horst, M., N. McClintock, and L. Hoey. 2017. The Intersection of A Review of the Literature. Journal of the American Planning Association, 83 (3): 277-295.

Hovorka, A. 2008. Transspecies Urban Theory: Chickens in an African City. Cultural Geographies, 15 (1): 95-117.
Hubert, D. B., P. Laurent, and P. Moustier. 2010. Review Article Sustainable Urban Agriculture in Developing Countries. A Review. Agronomy for Sustainable Development, 30 (1): 21-32.

Mazumdar, S. dan S. Mazumdar. 2012. Immigrant Home Gardens: Places of Religion, Culture, Ecology, and Family. Landscape and Urban Planning, 105(3) : 258-265.

Mcclintock, N. 2010. Why Farm The City ? Theorizing Urban Agriculture Through a Lens of Metabolic Rift. Cambridge Journal of Regions, Economy and Society 3(2): 191-207.

Metalisa, R., A.Saleh dan P. Tjitopranoto. 2014. The Role of Women Farmers Group Leader Toward The Sustainability Gardening. Jurnal Penyuluhan, 10(2): 158-170.

Mohri, H., S. Lahoti, O. Saito, A. Mahaligam, N. Gunatilleke, Irham, V. T., Hoang, G. Hitinayak, K. Takaechi dan S. Herath. 2013. Assessment of Ecosystem Services in Homegarden Systems in Indonesia, Sri Lanka, and Vietnam. Ecosystem Services, 5: 124136.

Mulato, F. 2008. Ketersediaan Ruang Terbuka Publik dengan Aktivitas Rekreasi Masyarakat Penghuni Perumnas Banyumanik. Skripsi. Semarang: Fakultas Teknik Universitas Diponegoro.

Poulsen, M. N. 2017. Cultivating Citizenship, Equity, and Social Inclusion? Putting Civic Agriculture Into Practice Through Urban Farming. Agriculture and Human Values, 34(1): 135-148.

Putri, A. S. 2017. Analisis Pemanfaatan Lahan Pekarangan di Desa Tamantirto Kabupaten Bantul Yogyakarta. Skripsi. Bogor: Institut Pertanian Bogor

Rezai, G., M. N. Shamsudin dan Z. Mohamed. 2016. Urban Agriculture: A Way Forward to Food and Nutrition 
Security in Malaysia. Procedia - Social and Behavioral Sciences, $216: 39-45$.

Saptana, Sunarsih, dan S. Friyatno. 2013. Prospect of the Model of Sustainable Food Houses Region ( M-KRPL ) and Its KRPL Replication. Forum Penelitian Agro Ekonomi, 31(1) 67-88.

Setyowati, D. L. 2008. Iklim Mikro dan Kebutuhan Ruang Terbuka Hijau di Kota Semarang. Jurnal Manusia dan Lingkungan, 15(3): 125-140.

Simatele, D. M. and T. Binns. 2008. Motivation and Marginalization in African Urban Agriculture: The Case of Lusaka, Zambia. Urban Forum, 19(1): 1-21.

Specht, K., T. Weith, K. Swoboda dan R. Siebert. 2016. Socially Acceptable Urban Agriculture Businesses. Agronomy for Sustainable Development, 36(1): 1-14.
Sugiyono. 2010. Metode Penelitian Kuantitatif, Kualitatif, dan RED. Bandung: CV Alfabeta.

Sulistyawati, E dan Nugraha, R. 2015. Efektivitas Kompos Sampah Perkotaan sebagai Pupuk Organik. Sekolah Ilmu dan Teknologi Hayati. Diakses pada tanggal 20 Februari 2018. https://www.researchgate. net/publication/267947725\%0AEFE KTIVITAS

Trendov, N. M. 2018. Annals of Agrarian Science Comparative Study on The Motivations that Drive Urban Community Gardens in Central Eastern Europe. Annals of Agrarian Sciences, 16(1): 85-89.

Turner, B. 2011. Embodied Connections: Sustainability, Food Systems and Community Gardens. Local Environment :The International Journal of Justice and Sustainability, 16(6): 509-522. 